\title{
Functional significance of dystrophin positive fibres in Duchenne muscular dystrophy
}

\author{
L V B Nicholson, M A Johnson, K M D Bushby, D Gardner-Medwin
}

\begin{abstract}
The age when boys lose the ability to walk independently is one of the milestones in the progression of Duchenne muscular dystrophy (DMD). We have used this as a measure of disease severity in a group of $\mathbf{3 0}$ patients with DMD and six patients with intermediate Duchenne/Becker dystrophy (D/BMD). Dystrophin analysis was performed on tissue sections and western blots of muscle biopsy specimens from these patients and the relationships that were found between clinical severity and abundance of dystrophin labelling are reported. All patients with intermediate D/BMD had dystrophin labelling that was detected on sections and blots. Weak dystrophin labelling was found in sections from 21/30 DMD cases and on blots in 18/30 cases. Two non-exclusive patterns of dystrophin labelling were observed on sections: very clear labelling on a small percentage of fibres (usually $<1 \%$ ) or very weak labelling on a much higher proportion (about 25\%). The mean age at loss of mobility among the DMD patients with no dystrophin labelling on tissue sections was 7.9 years (range 6.3-9.5) while the mean age among those with some labelling was 9.9 years (range 8.0-11.9); this is a significant difference. Quantitative estimates of dystrophin abundance were obtained from densitometric analysis of dystrophin bands on blots. In the whole group of 36 patients, a significant positive relationship was found between the abundance of dystrophin and the age at loss of independent mobility. It is concluded that even the very low concentrations of dystrophin found in DMD patients may have some functional significance.

(Arch Dis Child 1993; 68: 632-636)
\end{abstract}

Dystrophin is the protein product of the Xp21 gene which is defective in patients with Duchenne and Becker muscular dystrophy (DMD, BMD). ${ }^{1}$ Approximately $60 \%$ of patients have mutations that remove, or occasionally duplicate, sections of DNA from within the very large gene. ${ }^{23}$ The DNA is transcribed into RNA with the protein coding sequence contained in about 79 segments or exons, and the RNA is translated into protein. ${ }^{3}$ Dystrophin is a cytoskeletal protein with a globular amino domain, a central rod-like domain, and a globular carboxy domain. ${ }^{4}$ Immunolabelling of unfixed frozen tissue sections of biopsy specimens from normal subjects or from patients with non-Xp21 linked muscle diseases demonstrates that dystrophin is normally localised in a uniform manner at the periphery of muscle fibres, close to the membrane. ${ }^{5-7}$ In muscle biopsy specimens from BMD patients a considerable amount of variation in labelling intensity is usually observed - both between and within muscle fibres. In biopsy specimens from patients with DMD dystrophin appears to be severely deficient or undetectable. ${ }^{578}$

These observations led Monaco et al to suggest that the difference in clinical phenotype between DMD and BMD was due to the effect that different mutations had on protein synthesis. ${ }^{9}$ The properties of a protein depend on its amino acid sequence and the instruction to synthesise any particular amino acid is contained in a triplet of RNA nucleotides called a codon. The instruction to stop synthesis is also contained in certain codons. The 'open reading frame' is the name given to the alignment that will divide the nucleotide sequence into the correct triplets. It was proposed that BMD patients had gene deletions that removed intact codons so that the open reading frame could be maintained. This would result, for example, in the synthesis of a dystrophin molecule with an amino domain, a shorter than normal rod domain, and a carboxy terminal domain. Such a molecule might well be semifunctional. In contrast, it was predicted that DMD patients had deletions that included one third or two thirds of a codon, so that when the remaining RNA sequence was divided into triplets, the reading frame was shifted and no longer coded for the correct amino acids. Furthermore, a shift in the reading frame soon generates a premature stop codon, so that protein synthesis would be terminated very shortly after a frame shifting deletion. ${ }^{9}$ In these circumstances, a small truncated protein without a carboxy terminus would be produced, and such aberrant molecules are usually broken down very rapidly. ${ }^{10}$ Analysis of the mutations in lymphocyte DNA from many hundreds of DMD and BMD patients has proved that 'frame shift hypothesis' of Monaco et al is correct in over $90 \%$ of the cases studied, ${ }^{23}$ and this is accepted as the explanation for the lack of dystrophin in DMD patients.

Nevertheless, DMD biopsy specimens labelled with many different antibodies may show a small number of fibres which are clearly dystrophin positive. ${ }^{11-17}$ Labelling may occur even with carboxy terminal antibodies, ${ }^{14} 16$ and serial sections labelled with antibodies that recognise epitopes before and after frame shifting deletions may show immunoreactivity with the same few fibres or groups of fibres. ${ }^{18} 19$ This indicates that such muscle from patients with DMD contains very low concentrations of dystrophin that must have been synthesised from mRNA in which the reading frame had been restored. ${ }^{1820}$ As the presence of in-frame dystrophin molecules is associated with milder clinical phenotypes, the 
aim of this report is to answer the question: "is the level of dystrophin synthesis in DMD patients too low to have any functional significance?'

\section{Patients and methods \\ PATIENTS}

All the patients were examined at the Regional Neurosciences Centre of Newcastle General Hospital. Muscle biopsies were performed as part of the diagnostic procedure and specimens stored in a liquid nitrogen archive. The patients in this report were part of a cohort of 100 DMD and $B M D$ patients who were entered into a large multidisciplinary study (manuscript in preparation). Patients were selected if they had provided a muscle biopsy specimen and a blood sample for DNA deletion analysis, and the cohort consisted of the first 100 unrelated patients to satisfy these criteria. None of the DMD patients had undergone the Rideau procedure or had taken steroids. This report concentrates only on the 36 DMD or intermediate D/BMD patients who had lost mobility. These patients were divided into three groups according to their clinical condition using the age at which they lost the ability to walk independently (becoming confined to a wheelchair or able to walk only with the aid of full length callipers) as a measure of disease severity. The average age at loss of independent mobility in our entire population with DMD (not just those in this report) is just over 9 years. Group 1 were DMD patients who lost independent mobility between 6 and 9 years $(n=16)$, group 2 were patients with milder DMD who lost mobility between $9 \cdot 1$ and 12 years $(n=14)$, and group 3 were patients with intermediate D/BMD who lost mobility between $12 \cdot 1$ and 16 years $(n=6)$. Three DMD patients from the original cohort were excluded from this report because they had gene deletions which removed one of the antibody binding sites, thus producing a 'false negative' result for dystrophin analysis. Another boy with DMD was excluded because he had a completely atypical, Becker-like, pattern of dystrophin labelling. ${ }^{21}$

\section{MONOCLONAL ANTIBODIES}

The two monoclonal antibodies (MAbs) to dystrophin used in this study (Dy4/6D3: mid rod domain, Dy8/6C5: C terminus ${ }^{1922}$ ) are specific for dystrophin and lose all reactivity in tissue from patients who have a deletion in the Xp21 gene which removes the amino acids which form the antibody binding site..$^{23}$ The antibodies do not react with the chromosome 6 encoded dystrophin-like homologue, ${ }^{2526}$ which is also known as dystrophin related protein, 'DRP', or utrophin. ${ }^{27-29}$ The antibodies are available commercially from Novocastra Laboratories, Newcastle upon Tyne, under the names DYS1 and DYS2. Both antibodies label dystrophin weakly in tissue sections from biopsies of patients with $\mathrm{DMD}$, but only the rod $\mathrm{MAb}$ labels blots in the same proportion of patients. Dystrophin can be detected on blots of DMD muscle labelled with the $C$ terminal $M A b$, Dy8/6C5, but only in the cases of highest abundance. ${ }^{20} \mathrm{We}$ believe that the Dy8/6C5 epitope, at the extreme end of the $C$ terminal domain, is readily lost in the chemical and mechanical processing required for blotting, whereas it is retained in near native condition in unfixed tissue sections. ${ }^{19}$ In all our cases of Xp21 muscular dystrophy (including BMD) the abundance of dystrophin appears lower when blots are labelled with the $\mathrm{C}$ terminal MAb. ${ }^{19}$

\section{DYSTROPHIN ANALYSIS}

Immunocytochemical labelling and western blotting analysis of dystrophin size and abundance were performed as described previously. ${ }^{131922}$ Adjacent, rather than the same, blocks of tissue from open biopsies were generally used for the two types of analysis. Immunocytochemical labelling patterns were scored as negative ( - ), labelling on $<0 \cdot 1 \%$ fibres $( \pm)$, clear labelling on $<1 \%$ of fibres $(+)$, or as $>1 \%$ fibres with clear labelling and/or weak labelling on a higher proportion (about 25\%) of fibres $(++)$. These proportions were estimated by counting the number of dystrophin positive fibres and assessing the total number of fibres present (typically 3000-6000 in a section about $4 \mathrm{~mm}$ square). Dystrophin abundance, expressed as a percentage of normal, was estimated from densitometric analysis of the intensity of the dystrophin band labelling on blots (uppermost band in each lane). The staining of the myosin heavy chain band on the gel corresponding to each blot was used as a measure of the actual 'muscle' protein loaded (as opposed to fat and fibrous connective tissue). The principle is described in detail in a previous paper. ${ }^{19}$

\section{GENETIC ANAL YSIS}

Deletion analysis was performed on lymphocyte DNA digested with the restriction enzyme HindIII, blotted and analysed with dystrophin cDNA probes as described previously. ${ }^{320}$ The analysis was performed in the department of human genetics in the University of Newcastle upon Tyne, and in the department of human genetics, Sylvius Laboratory, Leiden, Netherlands, by courtesy of Professor Gert-Jan van Ommen. The effect of mutations on the open reading frame was determined using the data provided by Koenig et al. ${ }^{2}$ The state of the reading frame could not be assessed in patients with undetectable mutations or with unusually sized DNA fragments (junctional fragments). ${ }^{2}$

\section{STATISTICAL ANALYSIS}

Advice on the statistical analysis of the results was provided by $\mathrm{Mr} \mathrm{T}$ Butler in the department of medical statistics, University of Newcastle upon Tyne. Tests employed were the Student's $t$ test for comparison of two mean values, one way analysis of variance (ANOVA) for comparison of dystrophin abundance in different clinical groups and regression analysis for the correlation between age at loss of mobility and dystrophin abundance.

\section{Results}

Previously we have observed limited dystrophin 


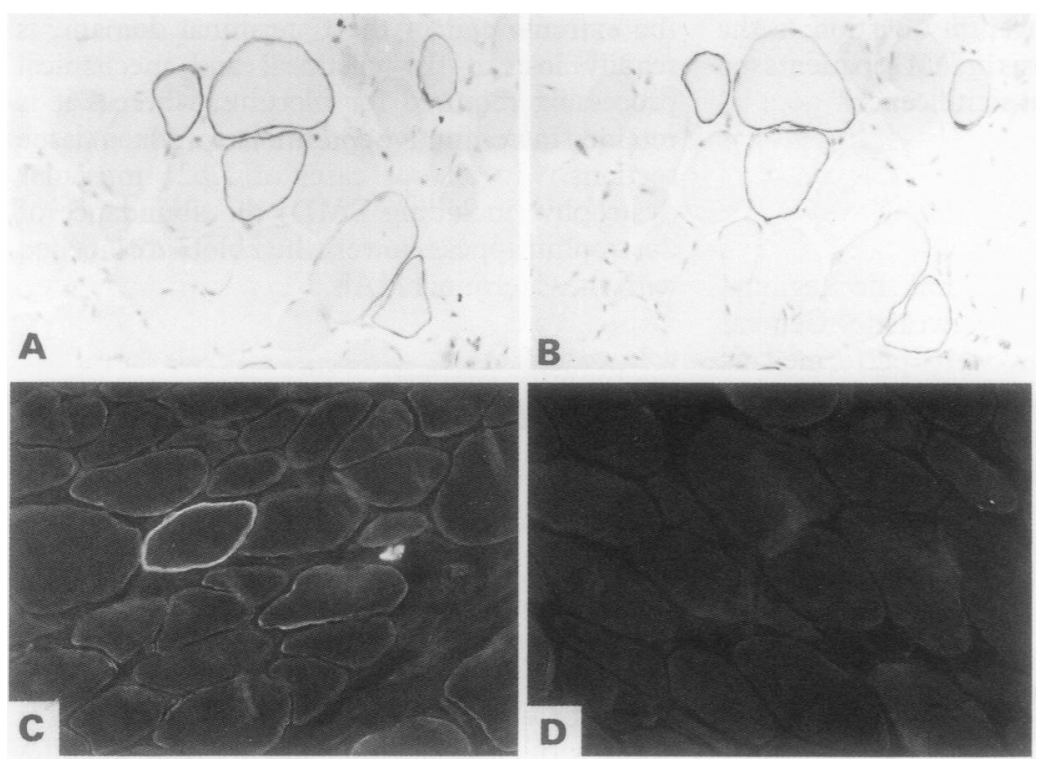

Figure 1 (A) Indirect peroxidase labelling of DMD muscle with the rod MAb Dy4/6D3. (B) Serial section to $(A)$ labelled with $C$ terminal MAb Dy8/6C5. The same few fibres show clear labelling of dystrophin. (C) Immunofluorescence labelling of DMD muscle with Dy4/6D3. One fibre with clear labelling is surrounded by others with very weak labelling.

(D) Immunofluorescence labelling of DMD muscle with Dy4/6D3. Fibres are dystrophin negative. All biopsy specimens are from patients with frame shifting gene deletions.

positive labelling in about $60 \%$ of DMD biopsy specimens. ${ }^{12} 1319$ Isolated fibres with clear dystrophin labelling (as in fig 1A) usually represent less than $1 \%$ of the total number of fibres present in a tissue section. The fibres can be labelled with the $\mathrm{C}$ terminal $\mathrm{MAb}$, indicating the presence of inframe dystrophin molecules (fig 1B). In addition to this very clear labelling, we have observed that some biopsy specimens may have a much larger proportion of fibres ( $25 \%$ or more) with very weak labelling on all or part of the surface. This type of immunoreactivity may be more conspicuous with a fluorescent than with a peroxidase label. Figure 1C shows a clear dystrophin positive fibre surrounded by other fibres which show weak labelling compared with the negative fibres in fig 1D.

In this report we have concentrated on the results obtained with the rod MAb, Dy4/6D3, which generally shows parallel labelling of sections and blots. Figure 2 shows a blot of some DMD and intermediate D/BMD muscle samples labelled with Dy4/6D3. The uppermost band

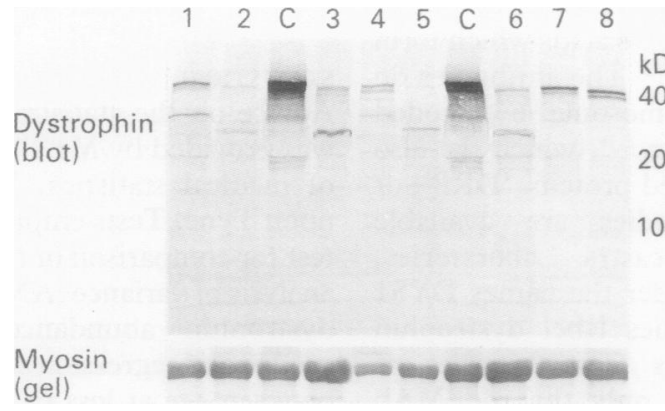

Figure 2 Western blot of DMD (lanes 1-5) and intermediate $D / B M D$ (lanes 6-8) muscle samples labelled with rod MAb Dy4/6D3. C= control muscle. Bands below the $400 \mathrm{kDa}$ doublet in the control lanes represent dystrophin metabolites. Lower panel shows Coomassie blue staining of myosin heavy chain on the corresponding gel.

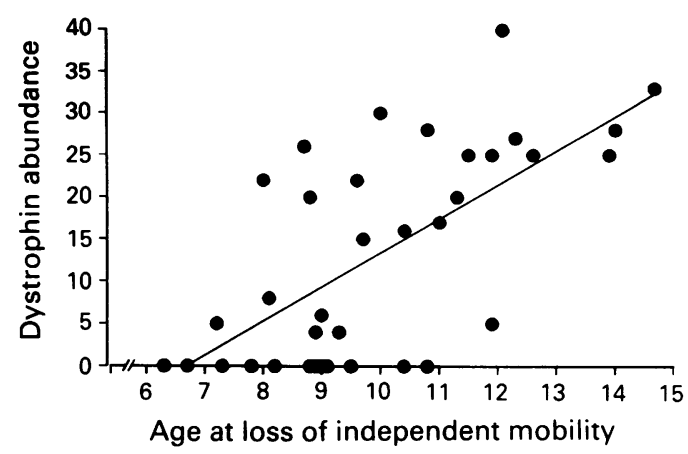

Figure 3 Age at loss of independent mobility and dystrophin abundance (\% of normal, estimated from blots labelled with $\operatorname{rod} M A b D y 4 / 6 D 3)$ in $36 D M D$ and intermediate $D / B M D$ patients. Data are from the table.

detected in each sample lane corresponded to full size or near full size dystrophin molecules and not to severely truncated polypeptides, although some lanes also contained bands of lower molecular mass which might correspond to prematurely terminated polypeptides. Thus a variable proportion of the dystrophin detected in individual DMD patients was of a size which was appropriate for synthesis from mRNA in which the reading frame had been restored. ${ }^{20}$

The table summarises the results of dystrophin analysis in each of the clinical groups. All the boys in the intermediate D/BMD group 3 had some dystrophin positive labelling on tissue sections. Among the 30 boys with 'classical' DMD in clinical groups 1 and 2, 21 had dystrophin labelling on some fibres. This is a slightly higher proportion than we find generally, and probably occurred by chance in the relatively small number of individuals in this report. The mean age at loss of mobility among the DMD patients with no dystrophin labelling on sections was 7.9 years (range 6.3-9.5) while the corresponding age among those with some labelling was 9.9 years (range $8 \cdot 0-11 \cdot 9$ ). A $t$ test shows that this is a significant difference $(t=3.96$ with $28 \mathrm{df}, \mathrm{p}<0.001)$. This also indicates that the boys with some dystrophin positive fibres stayed on their feet, on average, 24 months longer than those without any dystrophin.

The assessment of dystrophin labelling on tissue sections is qualitative but more quantitative estimates of dystrophin abundance can be obtained from densitometric analysis of the bands on blots. As can be seen in the table, the mean values for dystrophin abundance increase from group 1 to group 3 and there is a significant difference between the groups (one way ANOVA, $p<0.001)$. Overall, a highly significant positive relationship was found between dystrophin abundance and the age at loss of mobility in the 36 subjects (fig 3 , correlation coefficient, $r=0.67, \mathrm{p}<0.001$ ).

\section{Discussion}

The results presented in this report suggest that there is a relationship between the abundance of dystrophin in boys with DMD and their clinical severity, as indicated by the age at which they lose the ability to walk independently. The correlation, while statistically significant in a 
sample of this size, is not absolute and a few individuals with relatively high dystrophin concentrations lost mobility earlier than our population average of 9 years. Conversely, two boys with undetectable dystrophin labelling on blots (but a few fibres labelled on sections) maintained independent mobility until they were more than 10 years old. If we are correct in our interpretation of these data one explanation for these apparent discrepancies would be that some biopsy samples are not representative of the musculature as a whole. Our experiences (and those of many others) suggest that the distribution of dystrophin positive fibres can be very uneven: one fascicle being completely negative and the next containing a high proportion of immunoreactive fibres..$^{131630}$ This is supported by the observation that, although the results of labelling sections and blots generally matched each other (table), there are some instances when the use of different tissue blocks from the same biopsy produced slightly different results.

The immunocytochemical labelling of very clear dystrophin positive fibres is generally of the order of $1 \%$ of the fibre population, yet estimates of dystrophin abundance sometimes exceed $20 \%$. Why is there this discrepancy? Firstly, it seems very likely that the weak labelling of dystrophin around a high percentage of fibres makes a substantial contribution to the total dystrophin detected on blots. This type of label-

Age at loss of mobility and dystrophin analysis for individuals in different clinical groups

\begin{tabular}{|c|c|c|c|c|}
\hline $\begin{array}{l}\text { Age at loss of mobility } \\
\text { (years) }\end{array}$ & $\begin{array}{l}\text { Frame shift } \\
\text { produced by gene } \\
\text { mutation }\end{array}$ & $\begin{array}{l}\text { Labelling on } \\
\text { sections with } \\
\text { Dy4/6D3 }\end{array}$ & $\begin{array}{l}\text { Dystrophin abundance (\% of } \\
\text { normal) estimated from blots } \\
\text { labelled with Dy4/6D3 }\end{array}$ & $\begin{array}{l}\text { Blot lane } \\
\text { (see fig 2) }\end{array}$ \\
\hline \multicolumn{5}{|l|}{ Group $1(n=16)$} \\
\hline $6 \cdot 3$ & Yes & - & 0 & \\
\hline $6 \cdot 7$ & Yes & - & 0 & \\
\hline $7 \cdot 2$ & Yes & - & 5 & \\
\hline $7 \cdot 3$ & Yes & - & 0 & \\
\hline $7 \cdot 8$ & $?$ & - & 0 & \\
\hline 8.0 & $?$ & + & 22 & \\
\hline & $\dot{?}$ & + & 8 & \\
\hline $8 \cdot 2$ & Yes & \pm & 0 & \\
\hline 8.7 & Yes & $\overline{+}+$ & 26 & \\
\hline $\begin{array}{l}8 \cdot 8 \\
8.8\end{array}$ & Yes & $\overline{t+}$ & 20 & 1 \\
\hline $\begin{array}{l}8.8 \\
8.9\end{array}$ & $\begin{array}{l}\text { Yes } \\
?\end{array}$ & $\stackrel{++}{-}$ & $\begin{array}{r}20 \\
0\end{array}$ & 1 \\
\hline 8.9 & $\dot{?}$ & + & 4 & \\
\hline $9 \cdot 0$ & $?$ & \pm & 0 & \\
\hline $9 \cdot 0$ & Yes & - & 0 & \\
\hline 9.0 & Yes & + & & 5 \\
\hline \multicolumn{5}{|c|}{ Mean (SD) $5 \cdot 7(8 \cdot 9)$} \\
\hline Group $2(n=14)$ & & & & \\
\hline $9 \cdot 3$ & Yes & \pm & 4 & 2 \\
\hline $\begin{array}{l}9 \cdot 5 \\
9 \cdot 6\end{array}$ & $?_{\mathrm{Y}}^{\mathrm{es}}$ & - & 0 & \\
\hline $\begin{array}{l}9.6 \\
9.7\end{array}$ & Yes & $\begin{array}{l}++ \\
\pm\end{array}$ & $\begin{array}{l}22 \\
15\end{array}$ & \\
\hline $10 \cdot 0$ & Yes & ++ & 30 & \\
\hline $10 \cdot 4$ & No & \pm & 0 & \\
\hline 10.4 & Yes & + & 16 & \\
\hline 10.8 & Yes & \pm & 0 & \\
\hline 10.8 & No & $\overline{+}+$ & 28 & \\
\hline $11 \cdot 0$ & Yes & $+t$ & 17 & 3 \\
\hline $11 \cdot 3$ & Yes & + & 20 & \\
\hline 11.5 & $?$ & ++ & 25 & 4 \\
\hline 11.9 & Yes & + & 5 & \\
\hline 11.9 & Yes & ++ & & \\
\hline Mean 10.6 & & & Mean (SD) 14.8(11.0) & \\
\hline \multicolumn{5}{|l|}{ Group $3(n=6)$} \\
\hline $12 \cdot 1$ & & $++\star$ & 40 & \\
\hline $12 \cdot 3$ & $?$ & ++ & 27 & \\
\hline $\begin{array}{l}12.6 \\
13.9\end{array}$ & $\begin{array}{l}\text { No } \\
\text { Yes }\end{array}$ & $\begin{array}{l}++ \\
+\end{array}$ & $\begin{array}{l}25 \\
25\end{array}$ & 6 \\
\hline 14.0 & $\begin{array}{l}\text { Yes } \\
\text { Yes }\end{array}$ & ++ & 28 & 8 \\
\hline $14 \cdot 7$ & No & ++ & 33 & 7 \\
\hline
\end{tabular}

$?=$ Effect on reading frame cannot be assessed (no mutation detected or junctional fragment present). $\star=$ One whole fascicle dystrophin positive, rest of section had $<5 \%$ fibres labelled.

Negative $=-$, labelling on $<0 \cdot 1 \%$ fibres $= \pm$, clear labelling on $<1 \%$ of fibres $=+$, clear labelling on

Negative $=-$, labelling on $<0 \cdot 1 \%$ fibres $= \pm$, clear labelling on $<1 \%$ of fibres $=+$, clear labelling on
$>1$ fibres with clear labelling and/or weak labelling on a higher proportion (about $25 \%$ ) of fibres $=++$. ling was observed more frequently in the patients with milder DMD and intermediate D/BMD (that is, groups 2 and 3 ) and these were also the individuals with the highest dystrophin concentrations on blots. Secondly, in a blot all the dystrophin present in $\leq 200 \mu \mathrm{g}$ muscle homogenate is concentrated into a narrow band and presented with open access to primary and secondary antibodies.

The fact that dystrophin positive fibres are labelled by $\mathrm{C}$ terminal antibodies, ${ }^{14} 161819$ and that the size of the dystrophin bands on blots is within the range seen in BMD patients, ${ }^{13}$ indicates that at least some of the dystrophin detected in DMD patients is synthesised from mRNA in which the reading frame has been restored. ${ }^{1820}$ Our observations suggest that two different compensatory mechanisms may contribute to this effect. The very clear dystrophin positive fibres might contain dystrophin competent nuclei so that all gene products would be effectively 'in-frame'. In contrast, the very weak labelling on a high proportion of fibres might be due to a compensatory event at RNA transcript level. In either case, exon skipping or other forms of abnormal splicing may be involved. Any mechanism by which, for example, an exon 44 deletion (out of frame) could be enlarged to an exon 44-45 deletion (in-frame) would have the required effect. Exon skipping has been shown to occur in a number of individual cases, ${ }^{3132}$ but whether this is a more widespread occurrence is not currently known. A proportion of the patients with no detectable deletions have simple base pair substitutions or point mutations, ${ }^{33}$ and Klein $e t$ al recently suggested that the dystrophin positive fibres that they observed in two such DMD patients with no deletions might be the result of a secondary in-frame deletion that removed the original mutation..$^{18}$

An autosomal dystrophin-like homologue, DRP, ${ }^{278}$ which is restricted to neuromuscular junctions in normal muscle membranes, appears to be up-regulated around the sarcolemma in individuals (whether $m d x$ mice or human beings) with dystrophin deficiency..$^{25+37} \mathrm{We}$ are confident, however, that the protein that we observe with Dy4/6D3 and Dy8/6C5 antibodies in DMD muscle is not DRP. We have now raised monoclonal antibodies to DRP, ${ }^{38}$ which do not cross react with dystrophin, and have used them to label our DMD biopsy specimens. Initial experiments suggest that the labelling pattern is quite different from that described in this report for dystrophin. All the DMD patients, without regard to severity of disease expression, showed some DRP labelling on almost all muscle fibres.

In summary, we have shown that there seems to be a relationship between dystrophin abundance and clinical severity in patients with DMD. In a cohort of 36 patients, the more dystrophin detected, the longer the boys maintained the ability to walk independently, although there were individual exceptions to this general rule. As more of our patients lose mobility we will be able to confirm or revise our initial conclusion. This result may have some relevence to the assessment of myoblast transfer and gene replacement therapies. The low levels of 'inframe' dystrophin in DMD patients may be 
derived from a small percentage of fibres with quite strong labelling and/or a much higher proportion of fibres with very weak labelling. The latter pattern of labelling is likely to be the one with more functional significance.

\section{Addendum}

Studies of mRNA splicing in muscle are currently in progress to look for evidence of exon skipping.

We wish to thank the human genetics departments in Newcastle and Leiden for the gene mutation analysis. Thanks are also due to Keith Davison for his expertise in quantitative western blotting. The financial support of the Muscular Dystrophy Group of Great Britain, the Wellcome Trust and the Medical Research Council is gratefully acknowledged.

1 Hoffman EP, Brown RH, Kunkel LM. Dystrophin: the protein product of the Duchenne muscular dystrophy locus. protein product of the
Cell 1987; 51: $919-28$.

2 Koenig M, Beggs AH, Moyer M, et al. The molecular basis for Duchenne versus Becker muscular dystrophy: correlation of severity with type of deletion. Am $\mathcal{J}$. Hum Genet 1989; 45: severity

3 den Dunnen JT, Grootscholten PM, Bakker E, et al. Topography of the Duchenne muscular dystrophy (DMD) gene: FIGE and CDNA analysis of 194 cases reveals 115 deletions and 13 duplications. Am $\mathcal{F}$ Hum Genet 1989; 45 835-47.

4 Koenig M, Monaco AP, Kunkel LM. The complete sequence of dystrophin predicts a rod-shaped cytoskeletal protein Cell 1988; 53: 219-28.

5 Arahata $\mathrm{K}$, Ishiura $\mathrm{S}$, Ishiguro $\mathrm{T}$, et al. Immunostaining of skeletal and cardiac muscle surface membrane with antibody against Duchenne muscular dystrophy peptide. Nature 1988; 333: 861-3

6 Bonilla E, Samitt CE, Miranda AF, et al. Duchenne muscular dystrophy: deficiency of dystrophin at the muscle cell surface. Cell 1988; 54: 447-52.

7 Zubrzycka-Gaarn EE, Bulman DE, Karpati G, et al. The Duchenne muscular dystrophy gene product is localized in sarcolemma of human skeletal muscle. Nature 1988; 333 . 466-9.

8 Hoffman EP, Fischbeck KH, Brown RH, et al. Characterization of dystrophin in muscle-biopsy specimens from patients tion of dystrophin in muscle-biopsy specimens from patients
with Duchenne's or Becker's muscular dystrophy. $N$ Engl with Duchenne's or Becker.

9 Monaco AP, Bertelson CJ, Liechti-Gallati S, Moser H, Kunkel LM. An explanation for the phenotypic differences between patients bearing partial deletions of the DMD locus. Genomics 1988; 2: 90-5.

10 Hoffman EP, Kunkel LM. Dystrophin abnormalities in Duchenne/Becker muscular dystrophy. Neuron 1989; 2: 1019-29.

11 Shimizu T, Matsumura K, Hashimoto K, et al. A monoclonal antibody against a synthetic polypeptide fragment of dystrophin (amino acid sequence from position 215 to 264). Proceedings of the fapanese Academy 1988; 64B: 205-8.

12 Nicholson LVB, Davison K, Johnson MA, et al. Dystrophin in skeletal muscle: II. Immunoreactivity in patients with Xp21 muscular dystrophy. F Neurol Sci 1989; 94: 137-46.

13 Nicholson LVB, Johnson MA, Gardner-Medwin D, Bhattacharya S, Harris JB. Heterogeneity of dystrophin expression in patients with Duchenne and Becker muscula dystrophy. Acta Neuropathol (Berl) 1990; 80: 239-50.

14 Vainzof $M$, Zubrzycka-Gaarn EE, Rapaport D, et al. Immunofluorescence dystrophin study in Duchenne dystrophy through the concomitant use of two antibodies directed against the carboxy-terminal and the amino-terminal region of the protein. F Neurol Sci 1991; 101: 141-7.

15 Wakayama Y, Jimi T, Takeda A, et al. Immunoreactivity of antibodies raised against synthetic peptide fragments antibodies raised against synthetic peptide fragments
predicted from mid portions of dystrophin cDNA. I Neurol predicted from mid port
16 Voit T, Stuettgen P, Cremer M, Goebel HH. Dystrophin as a diagnostic marker in Duchenne and Becker muscular dystrophy. Correlation of immunofluorescence and western blot. Neuropediatrics 1991; 22: 152-62.

17 Arahata K, Beggs AH, Honda H, et al. Preservation of the Cterminus of dystrophin molecule in the skeletal muscle from Becker muscular dystrophy. 7 Neurol Sci 1991; 101: 148-56.

18 Klein CJ, Coovert DD, Bulman DE, Ray PN, Mendell JR, Burghes AHM. Somatic reversion/suppression in Duchenne muscular dystrophy (DMD): evidence supporting a framemuscular dystrophy (DMD): evidence supporting a framerestoring mechanism in rare dyst

19 Nicholson LVB, Johnson MA, Davison K, et al. Dystrophin or a 'related protein' in Duchenne muscular dystrophy? Acta Neurol Scand 1992; 86: 8-14.

20 Nicholson LVB, Bushby KMD, Johnson MA, Ginjaar HB, den Dunnen JT, van Ommen G-JB. Predicted and observed sizes of dystrophin in some patients with gene deletions that disrupt the open reading frame. F Med Genet 1992;29: 892-6.

21 Nicholson LVB, Bushby KMD, Johnson MA, GardnerMedwin D, Ginjaar HB. Dystrophin expression in Duchenne patients with 'in frame' gene deletions. NeuroDuchenne patients with
pediatrics 1993 (in press).

22 Nicholson LVB, Davison K, Falkous G, et al. Dystrophin in skeletal muscle: I. Western blot analysis using a monoclonal antibody. F Neurol Sci 1989; 94: 125-36.

23 England S, Nicholson LVB, Johnson MA, et al. Very mild muscular dystrophy associated with the deletion of $46 \%$ of dystrophin. Nature 1990; 343: 180-2.

24 Récan D, Chafey P, Leturcq F, et al. Are cysteine-rich and Cterminal domains of dystrophin critical for sarcolemmal terminal domains of dystrophin critical

25 Pons F, Augier N, Léger JOC, et al. A homologue of dystrophin is expressed at the neuromuscular junctions of
dy normal individuals and DMD patients, and of normal and mdx mice: immunological evidence. FEBS Lett 1991; 282: $161-5$.

26 Augier $\mathrm{N}$, Boucraut J, Léger J, et al. A homologue of dystrophin is expressed at the blood vessel membrane of DMD and BMD patients: immunological evidence. f Neurol Sci 1992; 107: 233-8.

27 Love DR, Hill DF, Dickson G, et al. An autosomal transcript in skeletal muscle with homology to dystrophin. Nature 1989; 338: 55-8.

28 Khurana TS, Hoffman EP, Kunkel LM. Identification of a chromosome 6-encoded dystrophin-related protein. F Biol Chem 1990; 265: 16717-20.

29 Blake DJ, Love DR, Tinsley J, et al. Characterisation of a 4.8 $\mathrm{kb}$ transcript from the Duchenne muscular dystrophy locus expressed in Schwannoma cells. Human Molecular Genetics 1992; 1: 103-9.

30 Hoffman EP, Garcia CA, Chamberlain JS, Angelini C, Lupski $\mathrm{JR}$, Fenwick R. Is the carboxyl-terminus of dystrophin required for membrane association? A novel, severe case of Duchenne muscular dystrophy. Ann Neurol 1991; 30: 60510.

31 Chelly J, Gilgenkrantz H, Lambert $M$, et al. Effect of dystrophin gene deletions on mRNA levels and processing in
Duchenne and Becker muscular dystrophies. Cell 1990; 63: Duchenn

32 Roberts RG, Barby TFM, Manners E, Bobrow M, Bentley DR. Direct detection of dystrophin gene rearrangements by analysis of dystrophin mRNA in peripheral blood lymphocytes. Am ₹ Hum Genet 1991; 49: 298-310.

33 Roberts RG, Bobrow M, Bentley DR. Point mutations in the dystrophin gene. Proc Natl Acad Sci USA 1992; 89: 2331-5.

34 Tanaka H, Shimizu T, Ozawa E. Expression of a dystrophinlike protein on the surface membrane of muscle cells in $\mathrm{mdx}$ mice. Proceedings of the fapanese Academy $1989 ; 65 \mathrm{~B}: 238-41$.
mate

35 Tanaka H, Ishiguro T, Eguchi C, Saito K, Ozawa E. Expression of a dystrophin-related protein associated with the skeletal muscle cell membrane. Histochemistry 1991; 96: $1-5$.

36 Ohlendieck K, Ervasti JM, Matsumura K, Kahl SD, Leveille CJ, Campbell KP. Dystrophin-related protein is localized to neuromuscular junctions of adult skeletal muscle. Neuron 1991; 7: 499-508.

37 Voit T, Haas K, Léger JOC, Pons F, Léger JJ. Xp21 Dystrophin and 6q dystrophin-related protein. Comparative 1991; 139: 969-76.

38 Bewick GS, Nicholson LVB, Young C, O'Donnell E, Slater CR. Different distributions of dystrophin and related proteins at nerve-muscle junctions. NeuroReport 1992; 3: proteins
$857-60$. 